Received: 20.11 .2018

Revised: 30.11 .2018

Accepted: 14.12 .2018

DOI: $10.17804 / 2410-9908.2018 .6 .018-026$

\title{
MECHANICAL ALLOYING AND FRACTURE FEATURES OF NON-EQUILIBRIUM Cu-Co ALLOYS
}

\author{
T. P. Tolmachev ${ }^{1, \text { a) }}$, V. P. Pilyugin ${ }^{1, \text { b)* }}$, A. M. Patselov ${ }^{1, c)}$, \\ A. I. Ancharov ${ }^{2,3, \text { d) }}$, and A. V. Inozemtsev ${ }^{1, \text { e) }}$ \\ ${ }^{I}$ M.N. Miheev Institute of Metal Physics, Ural Branch of the Russian Academy of Sciences, 18 S. Kovalevskoy St., \\ Ekaterinburg, 620108, Russian Federation \\ ${ }^{2}$ Institute of Solid State Chemistry and Mechanochemistry of the Siberian Branch of the RAS, 18 Kutateladze St., \\ Novosibirsk, 630128, Russian Federation \\ ${ }^{3}$ Novosibirsk State University, 1 Pirogova St., Novosibirsk, 630090, Russian Federation \\ a) iD https://orcid.org/0000-0001-9073-4507 tolmachev@imp.uran.ru;
b) iD https://orcid.org/0000-0002-5150-6605 pilyugin@imp.uran.ru;
c) iD https://orcid.org/0000-0001-6438-0725 patselov@imp.uran.ru;
d) iD https://orcid.org/0000-0003-2258-437X ancharov@ mail.ru;
e) iD https://orcid.org/0000-0002-1737-6050 avinz@imp.uran.ru \\ *Corresponding author. E-mail: pilyugin@imp.uran.ru \\ Address for correspondence: ul. S. Kovalevskoy, 18, Ekaterinburg, 620108, Russian Federation \\ Tel.: +7 (343) 37838 05; fax: +7 (343) 3745244
}

The paper studies the structural, phase and fractographic features of mechanically synthesized non-equilibrium $\mathrm{Cu}-\mathrm{Co}$ alloys characterized by limited solubility. The components are taken in three different proportions. Mechanical alloying was carried out by high-pressure torsion related to severe plastic deformation methods. As a result of mechanical alloying, the investigated system of components initially insoluble below $800{ }^{\circ} \mathrm{C}$, according to the equilibrium phase diagram, undergoes structural and phase changes consisting in the formation of non-equilibrium solid solutions. With an increase in the proportion of cobalt in the original mixture, the proportion of this element in the solid solution increases after mechanical alloying. This, in turn, affects the appearance of the fracture surface; namely, it changes from brittle-ductile fracture first to brittle fracture and then to mixed one, corresponding to an earlier stage of deformation-induced mechanical alloying.

Keywords: mechanical alloying, high-pressure torsion, non-equilibrium solid solution, $\mathrm{Cu}-\mathrm{Co}$ system, fractography, X-ray diffraction analysis.

\section{Acknowledgment}

The research was performed within UB RAS Project No. 18-10-2-24.

\section{References}

1. Lyakishev N.P., ed. Diagrammy sostoyaniya dvoinykh metallicheskikh sistem [State Diagrams for Double Metal Systems: Reference book]. Moscow, Mashinostroenie Publ., 1997, 1024 p. (In Russian).

2. Miedema A.R., De Chatel P.F., De Boer F.R. Cohesion in alloys - fundamentals of a semiempirical model. Physica B, 1980, vol. 100, pp. 1-28. DOI: 10.1016/0378-4363(80)90054-6.

3. Barabash O.M., Koval Yu.N. Struktura i svoystva metallov i splavov [Structure and Properties of Metals and Alloys]. Kiev, Naukova Dumka Publ., 1986, 599 p. (In Russian). 
4. Tolmachev T.P., Pilyugin V.P., Ancharov A.I., Chernyshov E.G., Patselov A.M. The Formation, Structure, and Properties of the Au-Co Alloys Produced by Severe Plastic Deformation under Pressure. Physics of Metals and Metallography, 2016, vol. 117, no. 2, pp. 135-142. DOI: $10.1134 /$ S0031918X16020125.

5. Starenchenko V.A., Cherepanov D.N., Solov'eva Yu.V., Popov L.E. Generation and accumulation of point defects in fcc single crystals upon plastic strain. Russ. Phys. J., 2009, vol. 52, no. 4, pp. 398-410. DOI: 10.1007/s11182-009-9237-0.

6. Gapontsev V.L., Kondrat'ev V.V. Diffusion phase transformations in nanocrystalline alloys under severe plastic deformation. Dokl. Phys., 2002, vol. 47, no. 8, pp. 576-579. DOI: 10.1134/1.1505513.

7. Farber V.M. Contribution of diffusion processes to structure formation in intense cold plastic deformation of metals. Metal Sci. Heat Treat., 2002, vol. 44, no. 7-8, pp. 317-323. DOI: $10.1023 / \mathrm{A}: 1021216122980$.

8. Hirth J.P., Lothe J. Theory of Dislocations, New York, McGraw Hill, 1968, 780 p.

9. Shtremel' M.A. Participation of diffusion in the processes of mechanical alloying. Metal Sci. Heat Treat., 2002, vol. 44, no. 7-8, pp. 324-327. DOI: 10.1023/A:1021268107050.

10. Oberdorfer B., Setman D., Steyskal E., Hohenwarter A., Sprengel W., Zehetbauer M., Pippan R., Wurschum R. Grain boundary excess volume and defect annealing of copper after high pressure torsion. Acta Mater., 2014, vol. 68, pp. 189-195. DOI: 10.1016/j.actamat.2013.12.036.

11. Popov V.V., Sergeev A.V., Arkhipova N.K., Istomina A.Yu. Determination of the parameters of grain-boundary diffusion and segregation of $\mathrm{Co}$ in $\mathrm{W}$ using an improved model of grain-boundary diffusion. Phys. Met. Metallogr., 2011, vol. 112, pp. 256-266. DOI: 10.1134/S0031918X11030252.

12. Christian J. The Theory of Transformations in Metals and Alloys. Part 1. Equilibrium and General Kinetic Theory, Oxford, Pergamon, 1975, 586 p.

13. Andrievskii R.A., Glezer A.M. Strength of nanostructures. Phys. Usp., 2009, vol. 52, no. 4, pp. 315-334. DOI: 10.3367/UFNe.0179.200904a.0337.

14. Andrievskii R.A., Glezer A.M. Size effects in nanocrystalline materials. II. Mechanical and physical properties. Phys. Met. Metallogr., 2000, vol. 89, pp. 83-102.

15. Pilyugin V.P., Gapontseva T.M., Chashchukhina T.I., Voronova L.M., Shchinova L.I., Degtyarev M.V. Evolution of the structure and hardness of nickel upon cold and lowtemperature deformation under pressure. Phys. Met. Metallogr., 2008, vol. 105, pp. 409-418. DOI: $10.1134 / \mathrm{S} 0031918 X 08040157$. 
Подана в журнал: 20.11.2018

УДК 669.35+669.25:539.89

DOI: $10.17804 / 2410-9908.2018 .6 .018-026$

\title{
МЕХАНИЧЕСКОЕ СПЛАВЛЕНИЕ И ОСОБЕННОСТИ РАЗРУШЕНИЯ НЕРАВНОВЕСНЫХ СПЛАВОВ СИСТЕМЫ Со-Сu
}

\author{
Т. П. Толмачев ${ }^{1, \text { a) }}$ В. П. Пилюгин ${ }^{1, \text { б)* }}$ А. М. Пацелов ${ }^{1, \text { в), }}$ \\ А. И. Анчаров ${ }^{2,3, \text { г) }}$, А. В. Иноземцев ${ }^{1, \text { д) }}$ \\ ${ }^{1}$ Институт физики металлов им. М.Н.Михеева УрО РАН, \\ 620108, ул. С. Ковалевской, 18, г. Екатеринбург, Российская Федераџия \\ ${ }^{2}$ Институт химии твердого тела и механохимии СО РАН, \\ 630128, ул. Кутателадзе, 18, г. Новосибирск, Российская Федераиия \\ ${ }^{3}$ Новосибирский государственный университет, \\ 630090, ул. Пирогова, 1, Новосибирск, Российская Федераиия \\ a) (D) 0000-0001-9073-4507 인 tolmachev@imp.uran.ru; \\ b) (iD 0000-0002-5150-6605 ilyugin@imp.uran.ru; \\ c) (iD 0000-0001-6438-0725 @ patselov@imp.uran.ru; \\ d) iD 0000-0003-2258-437X $\otimes$ ancharov@ mail.ru; \\ e) (iD 0000-0002-1737-6050@ avinz@imp.uran.ru

\begin{abstract}
*Ответственный автор. Электронная почта: pilyugin@imp.uran.ru
Адрес для переписки: ул. С. Ковалевской, 18, 620108, г. Екатеринбург, Российская Федерация Тел.: +7 (343) 378-38-05; факс: +7 (343) 374-52-44
\end{abstract}

В работе изучаются структурно-фазовые и фрактографические особенности механически синтезированных неравновесных сплавов системы с ограниченной растворимостью $\mathrm{Cu}-\mathrm{Co}$, компоненты которой брали в трех различных пропорциях. Механическое сплавление осуществляли методом интенсивной пластической деформации - кручением под высоким давлением. В результате механосплавления исследуемая система исходных отдельных нерастворимых ниже $800{ }^{\circ} \mathrm{C}$ компонентов, согласно равновесной фазовой диаграмме, испытывает структурно-фазовые изменения, которые заключаются в формировании неравновесных твердых растворов. С увеличением доли кобальта в шихте доля его в твердом растворе после механосплавления увеличивается. Это в свою очередь влияет на вид поверхности разрушения, когда от хрупко-вязкого излома происходит переход сначала к хрупкому сколу, а затем к смешанному, соответствующему более ранней стадии деформационно-индуцированного механического сплавления.

Ключевые слова: механическое сплавление, кручение под высоким давлением, система $\mathrm{Cu}-\mathrm{Co}$, неравновесный твердый раствор, фрактография, рентгеновская дифрактометрия.

\section{1. Введение}

Система $\mathrm{Cu}-\mathrm{Co}$ имеет ограниченную растворимость компонентов. Так при температуpe $800{ }^{\circ} \mathrm{C}$ растворимость со стороны кобальта не более 3 ат. \%, а со стороны меди не более 1,5 ат. \% (рис. 1). Ограниченность взаимной растворимости данной системы объяснить нарушением правила Юм-Розери, разница ионных радиусов меди и кобальта составляет более $15 \%$. [1, 2]. Имеется интерес определения условий формирования, исследование структуры и механических свойств сплавов $\mathrm{Cu}-\mathrm{Co}$ в концентрациях, существенно превышающих равновесное состояние как основы создания реметаллических присадок. Используемые для синтеза неравновесных сплавов методы интенсивного воздействия, такие как быстрая закалка, шаровой помол, взрывная обработка и др., позволяют получать материал в дисперсном 
виде, что затрудняет измерения механических свойств, в плане пластичности, твердости и характера разрушения.

Для решения задачи целесообразно получать образцы в цельном виде при контролируемых температурно-скоростных и по величине деформации условиях, что достигается в методе сдвига в камере Бриджмена под высоким давлением, или, иначе, кручения под высоким давлением (КВД) [3].

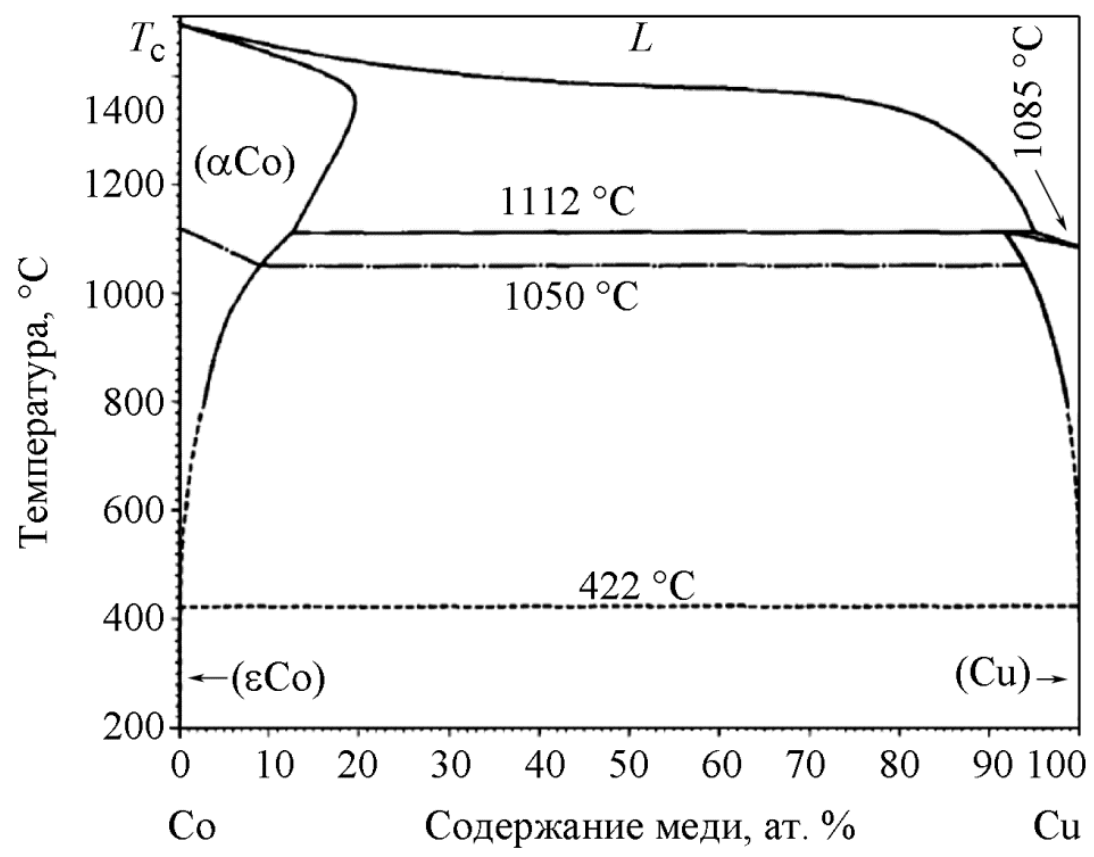

Рис. 1. Равновесная фазовая диаграмма системы $\mathrm{Cu}-\mathrm{Co}$ [1]

Таким образом, основные цели исследования - определение условий и выявление особенностей механического сплавления исходно порошковых компонентов Со и Си различных составов, кинетики процессов механического сплавления и изучение микроструктуры полученных сплавов и видов их разрушения.

\section{2. Материал и методика}

Процедура обработки материалов для механического сплавления (МС) заключалась в следующем. Исходные компоненты в виде порошковых смесей помещались между наковален Бриджмена, представляющих собой усеченные конусы и состоящие из сверхтвердого сплава ВК-6. Диаметр рабочих площадок наковален составлял 5 мм, давление обработки около 8 ГПа, температура - соответствующая комнатной, около 293 К, скорость вращения одной наковальни относительно другой - 1 об./мин. Деформацию всех составов смесей производили на 5 оборотов наковальни.

Компоненты исследуемой системы брали в трех различных соотношениях: с преимущественным содержанием меди (80 ат. \% Сu и 20 ат. \% Со), эквиатомный состав $(50$ ат. \% Cu и 50 ат. \% Со) и состав с преимущественным содержанием кобальта (20 ат. \% Сu и 80 ат. \% Со). Размеры частиц порошковых компонентов составлял не более 100 мкм, рис. 2. 


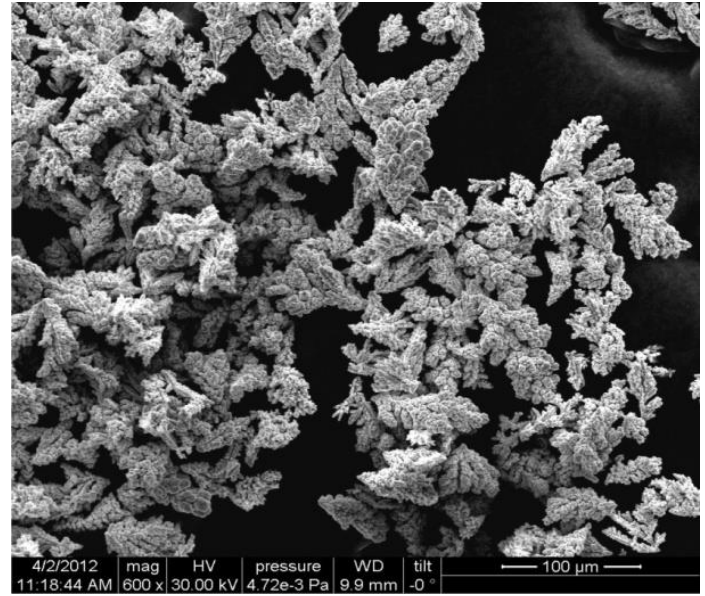

$a$

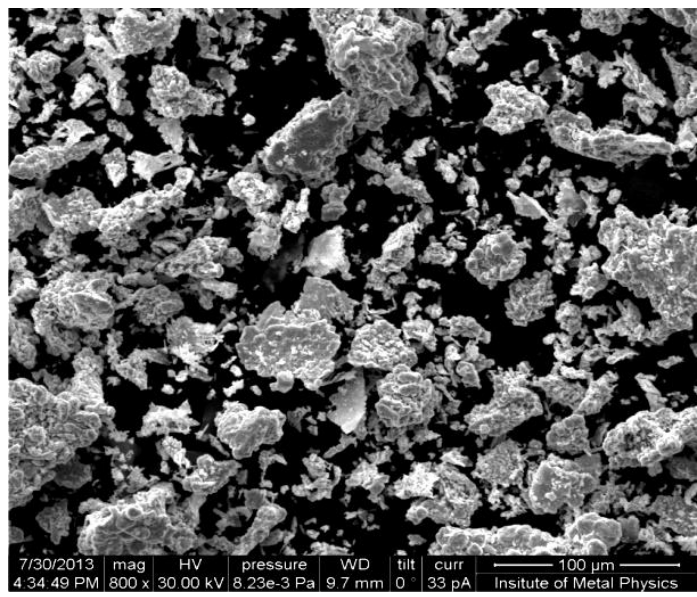

$\sigma$

Рис. 2. Исходное состояние сплавляемых компонентов системы $\mathrm{Cu}-\mathrm{Co}$ в сканирующем электронном микроскопе: $a-$ медь; $\sigma$ - кобальт

Сплавы в результате КВД имели форму линзообразных дисковых образцов диаметром 5 мм и толщиной в центре диска 100 мкм и до 30 мкм на краях, что обеспечивало возможность проведения изучения микроструктуры их изломов, химического состава и выполнения рентгеновской дифрактометрии. Структурные и фазовые изменения с ростом деформации изучали с помощью рентгеновской дифрактометрии на аппарате ДРОН-3 в $\mathrm{CuK \alpha} \alpha$-излучении $(0,154$ нм) в геометрии на отражение со всей поверхности образца в диапазоне углов дифракции 2и от 40 до $100^{\circ}$. Расчет периода кристаллической решетки фазы с ГЦК-структурой проводили по 2-3 последним линиям, которые располагаются в области углов более $60^{\circ}$. Для изучения поверхности разрушения образцов производили их излом методом изгиба в среде жидкого азота. Изображения поверхностей излома получали в сканирующем электронном микроскопе Quanta 200 на расстоянии половины радиуса образца с охватом в 50 мкм в обе стороны с увеличением в 2000 раз.

\section{3. Результаты и обсуждение}

Рентгеновские дифрактограммы от образцов системы $\mathrm{Cu}-\mathrm{Co}$ трех составов, полученных КВД на 5 оборотов наковален, приведены в узком диапазоне углов $2 \theta$ (рис. 3). Вместе с дифракционными спектрами приведен также спектр, который соответствует смеси меди и кобальта до деформации, взятой в эквиатомной пропорции. Кроме того, приведены литературные данные по расположению рефлексов меди и кобальта для отождествления фазового состава системы, как до деформации, так и после нее. Некоторое смещение пиков обусловлено высокой дисперсностью порошков компонентов, а также вероятным наличием примесей типа оксидной пленки и (или) обусловлены методикой получения.

Специфической особенностью I-2ө дифрактограмм механосинтезированных образцов (рис. $3 ; 2,3$ и 4) является резкое снижение интенсивности вторых и последующих пиков, сильный рост уширений пиков по мере роста концентраций кобальта в исходной шихте полученных образцов в последовательности составов Сu80Co20, Cu50Co50, Cu20Co80. Этот эффект можно объяснить разницей ионных радиусов меди и кобальта. Ионный радиус меди на 15,8 \% превышает ионный радиус кобальта. Таким образом, увеличение кобальта в шихте вызывает уменьшение размеров областей когерентного рассеяния и увеличение внутренних напряжений. 


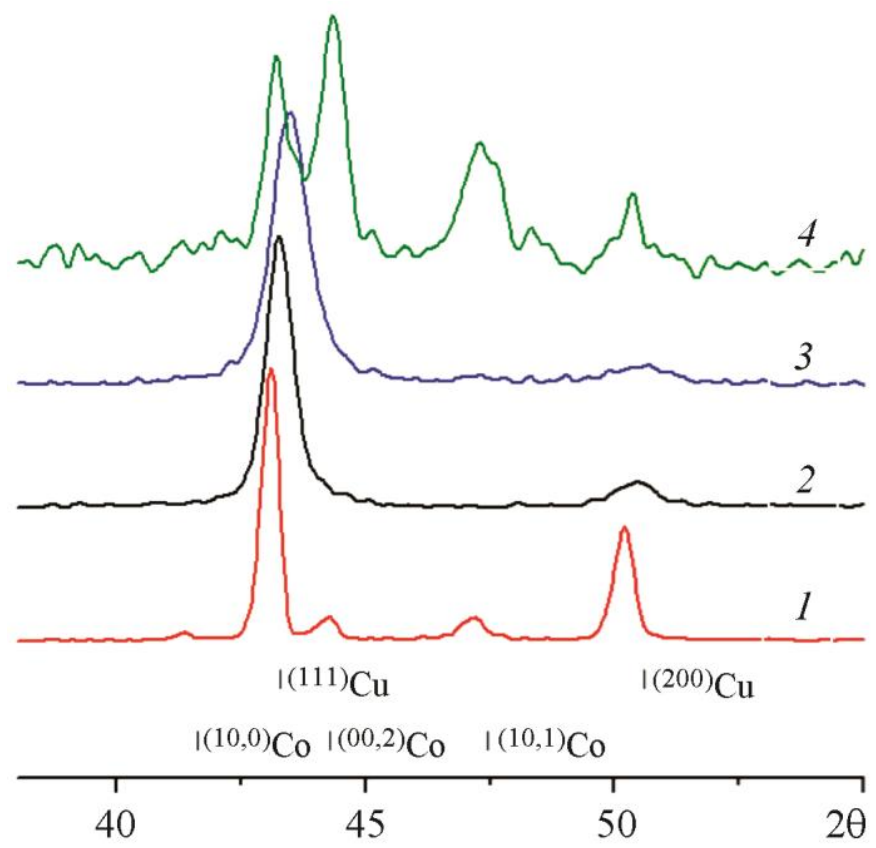

Рис. 3. Рентгеновские дифрактограммы компонентов системы $\mathrm{Cu}$ и Со в порошковом состоянии и после механосплавления: 1 - Недеформированная смесь состава 50:50; 2 - после МС состава 80:20; 3 - 50:50; 4 - 20:80

Для первых двух составов (рис. 3; 2 и 3) КВД привело к почти полному исчезновению ряда пиков кобальта, что связано с деформационно индуцированным формированием твердого раствора замещения кобальта в матрице меди.

В результате увеличения доли кобальта в шихте, интенсивность рефлексов от фазы на основе меди снижается по сравнению с рефлексами от фазы на основе кобальта, при этом интенсивность всех пиков низкая и близка к фону (рис. $3 ; 3$ и 4). Кроме того, по спектрам заметно, что положение пиков, связанных с фазой на основе меди, претерпевает изменение, при этом с увеличением содержания кобальта в исходной смеси от 20 до 50 ат. \% происходит смещение пиков меди в сторону больших углов.

Известно, что в данной системе постепенное растворение кобальта в матрице меди будет приводить к уменьшению периода кристаллической решетки твердого раствора [3], что будет отвечать смещению пиков от фазы на основе меди в сторону больших углов дифракции. В табл. 1 приведены значения периодов неравновесных твердых растворов на основе меди, расчитанных по дифрактограммам (рис. 3). В случае исходного состава $\mathrm{Cu} 80 \mathrm{Co} 20$ ат. \% с преимущественной долей меди период решетки твердого раствора весьма близок к периоду решетки чистой меди. С увеличением доли кобальта в шихте значение периода решетки снижается, свидетельствуя о постепенном растворении кобальта в матрице меди. При этом преодолевается пороговое значение в 3,607 А, которое соответствует максимально возможной растворимости в 8 ат. \% Со при $1110^{\circ} \mathrm{C}$ на равновесной фазовой диаграмме $\mathrm{Cu}-\mathrm{Co}[3]$.

Таблица 1 - Значения периодов кристаллической решетки меди в исходном состоянии

\begin{tabular}{|c|c|c|c|}
\hline \multirow{2}{*}{$\begin{array}{c}\text { Поворот } \\
\text { наковальни }\end{array}$} & Сu80Со20, ат. \% & Сu50Со50, ат. \% & Сu20Со80, ат. \% \\
\cline { 1 - 4 } & $a_{\mathrm{cp}}($ ГЦК $) \AA$ & $a_{\mathrm{cp}}($ ГЦК $), \AA$ & $a_{\mathrm{cp}}($ ГЦК $), \AA$ \\
\hline Исходное состояние & 3,620 & 3,625 & 3,623 \\
\hline$n=5$ & 3,617 & 3,598 & 3,587 \\
\hline
\end{tabular}


Изломы образцов таких сплавов, приведенные на рис. 2, показывают изменения типа излома при изменении доли кобальта в составе исходной смеси. На рис. $2 a$ выявляются два типа поверхности разрушения: приповерхностные области и центральная область, ограниченная приповерхностными. Области, более близкие к наковальням, в процессе обработки испытали значительно большую деформационную проработку структуры, вследствие чего образовался сплошной, ровный излом по типу хрупкого скола. В то же время в центральной области на рис. $4 a$ имеются участки, которые подверглись меньшей деформационной обработке.

Промежуточный случай излома от образца эквиатомного состава отличается от двух предыдущих однородным типом поверхности разрушения, аналогичным излому боковых приповерхностных участков. По данным рентгеновской дифрактометрии эквиатомного состава, 50:50 смещение пика фазы твердого раствора на основе меди значительнее, чем в случае 80:20. Таким образом, в данном случае сформировался твердый раствор с большим содержанием кобальта, по положению пиков на дифрактограмме 3 и значению периода кристаллической решетки, и однородным типом излома [5].

При дальнейшем увеличении доли кобальта в шихте поверхность излома образцов весьма неоднородна и отвечает более ранним стадиями деформационных превращений, которые соответствуют формированию слоистых структур из компонентов. На нем как визуально, так и по анализу характеристического излучения можно определить частицы недорастворившегося чистого кобальта и образовавшегося твердого раствора (рис. 4 в).

Таким образом, в зависимости от пропорции меди и кобальта в шихте изменяется тип излома механосинтезированного сплава: хрупко-вязкий (рис. 4 a) в случае состава 80:20), хрупкий по типу скола, однородный и равномерный по рельефу поверхности и смешанного типа в случае пропорции меди и кобальта 20:80 в ат. \%.

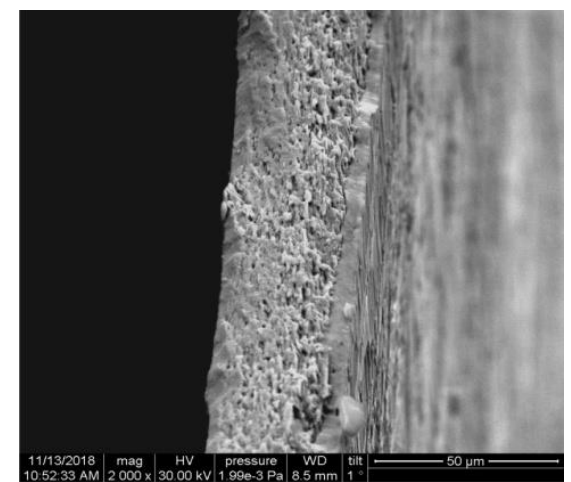

$a$

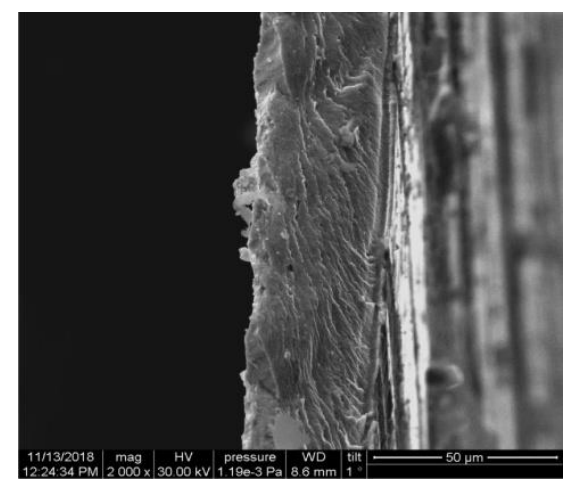

$\sigma$

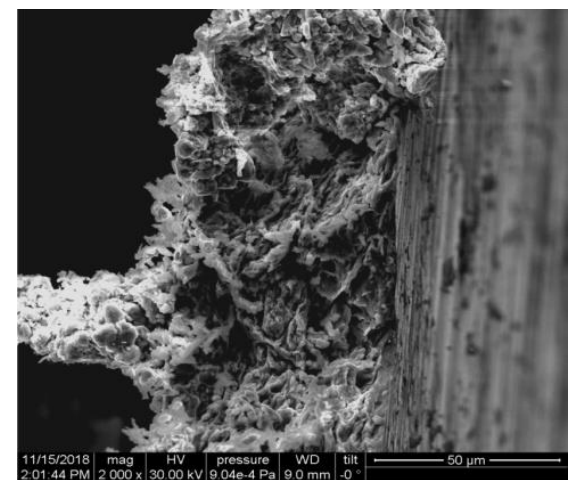

B

Рис. 4. Изображения изломов сплавов системы $\mathrm{Cu}-\mathrm{Co}$, полученные в СЭМ, на середине радиусов образов состава: $a-80: 20 ; \sigma-50: 50 ; в-20: 80$

Увеличение содержания кобальта в исходной шихте приводит к замедлению механического сплавообразования по причине необходимости деформационного измельчения частиц кобальта, а также перемешивания на кластерном уровне его частиц с частицами меди на ранних стадиях деформационной обработки; а на более поздних этапах, связанных непосредственно с процессом механического растворения, - по причине замещения атомами меди атомов кобальта в его кристаллической решетке, в силу большего размера атомов меди по сравнению с атомами кобальта.

Деформация порошковых смесей $\mathrm{Cu}-\mathrm{Co}$ вызывает протекание ряда взаимосвязанных процессов на различных масштабных уровнях, способствующих смешиванию атомов исходных компонентов, и тем самым приводит к формированию твердых растворов. В числе их:

- активная генерация неравновесных точечных дефектов $[5,6]$;

- диффузия по дислокационным трубкам [7];

Mechanical alloying and fracture features of non-equilibrium Cu-Co alloys / T. P. Tolmachev, V. P. Pilyugin, A. M. Patselov, A. I. Ancharov, A. V. Inozemtsev // Diagnostics, Resource and Mechanics of materials and structures. - 2018. - Iss. 6. P. 18-26. - DOI: 10.17804/2410-9908.2018.6.018-026. 
- захват и перенос атомов движущимися дислокациями [8];

- увеличение площади контактов компонент на несколько порядков при их взаимном пластическом утонении до субмикронного уровня $[9,10]$;

- зернограничная (межкристаллитная) диффузия [11];

- стресс диффузия (восходящая или диффузия под напряжением) [12];

- высокая (до 25-30 \%) доля межкристаллитного пространства (субграницы, границы нанозерен (нанокристаллитов), тройные стыки, четвертные стыки), как следствие деформационной фрагментации [13-15].

Совокупность порождаемых деформацией перечисленных процессов и дефектов частично определяет механизмы образования твердых растворов.

\section{4. Заключение}

Методом КВД проведено механическое сплавление порошков меди и кобальта в концентрациях существенно превышающих концентрацию равновесных твердых растворов. Сплавы имеют высокодефектную ГЦК-структуру неравновесного твердого раствора на основе меди с высоким уровнем остаточных напряжений и областей когерентного рассеяния малых размеров.

В зависимости от пропорции меди и кобальта в шихте изменяется тип излома механически синтезированного сплава: хрупко-вязкий (в случае соотношения меди и кобальта 80:20), хрупкий по типу скола, однородный и равномерный по рельефу поверхности (в случае эквиатомного соотношения) и неоднородного типа, характеризующий незавершенность процессов механосплавления (в случае пропорции меди и кобальта 20:80), ат. \%.

При выбранных условиях обработки (идентичных для всех составов) механически синтезированный сплав состава с $\mathrm{Cu} 20$ ат. \% и Со 80 ат. \% нельзя считать однородным материалом. Для достижения его однородности требуется интенсификация КВД-обработки в сторону повышения величины деформации и (или) снижение гомологической температуры деформации [4].

\section{Благодарность}

Исследование выполнено за счет проекта УрО РАН № 18-10-2-24.

\section{Литература}

1. Диаграммы состояния двойных металлических систем : справочник в 3 т. / под общ. ред. Н. П. Лякишева. - М. : Машиностроение, 1997. - 1024 с.

2. Miedema A. R., De Chatel P. F., De Boer F. R. Cohesion in alloys - fundamentals of a semiempirical model // Physica B. - 1980. - Vol. 100. - P. 1-28. - DOI: 10.1016/0378-4363(80)90054-6.

3. Барабаш О. М., Коваль Ю. Н. Структура и свойства металлов и сплавов. - Киев : Наукова думка, 1986. - 599 с.

4. Образование, структура и свойства сплавов системы $\mathrm{Au}-\mathrm{Co}$, полученных интенсивной пластической деформацией под давлением / Т. П. Толмачев, В. П. Пилюгин, А. И. Анчаров, Е. Г. Чернышев, А. М. Пацелов // Физика металлов и металловедение. - 2016. - № 2 (117). C. 155-163. - DOI: 10.7868/S0015323016020121.

5. Генерация и накопление точечных дефектов в процессе пластической деформации в монокристаллах с ГЦК-структурой / В. А. Старенченко, Д. Н. Черепанов, Ю. В. Соловьева, Л. Е. Попов // Известия высших учебных заведений. Физика. - 2009. - № 4. - С. 60-71.

6. Гапонцев В. Л., Кондратьев В. В. Диффузионные фазовые превращения в нанокриталлических сплавах при интенсивной пластической деформации // Доклады Академии наук. 2002. - Т. 385, № 5. - С. 608-611. 
7. Фарбер В. М. Вклад диффузионных процессов в структурообразовании при интенсивной холодной пластической деформации металлов // Металловедение и термическая обработка металлов. - 2002. - № 8. - С. 3-9.

8. Хирт Дж., Лоте И. Теория дислокаций / пер. с англ. под ред. Э. М. Надгорного, Ю. А. Осипьяна. - М. : Атомиздат, 1972. - 600 с.

9. Штремель М. А. Об участии диффузии в процессах механического легирования // Металловедение и термическая обработка металлов. - 2002. - № 8. - С. 10-12.

10. Grain boundary excess volume and defect annealing of copper after high pressure torsion / B. Oberdorfer, D. Setman, E. Steyskal, A. Hohenwarter, W. Sprengel, M. Zehetbauer, R. Pippan, R. Wurschum // Acta Mater. - 2014. - Vol. 68. - P. 189-195. - DOI: 10.1016/j.actamat.2013.12.036.

11. Определение параметров зернограничной диффузии и сегрегации Со в $\mathrm{W}$ с использованием уточненной модели зернограничной диффузии / В. В. Попов, А. В. Сергеев, Н. К. Архипова, А. Ю. Истомина. // Физика металлов и металловедение. - 2011. - № 3 (112). - С. 273-284.

12. Кристиан Дж. Теория превращения в металлах и сплавах. Ч. 1 : Термодинамика и общая кинетическая теория. - М. : Мир, 1978. - 806 с.

13. Андриевский Р. А., Глезер А. М. Прочность наноструктур // Успехи физических наук. 2009. - T. 179, № 4. - C. 337-358. - DOI: 10.3367/UFNr.0179.200904a.0337.

14. Андриевский Р. А., Глезер А. М. Размерные эффекты в нанокристаллических материалах: II. Механические и физические свойства // Физика металлов и металловедение. - 2000. - Т. 89, № 1. - C. 91-112.

15. Эволюция структуры и твердости никеля при холодной и низкотемпературной деформации под давлением / В. П. Пилюгин, Т. М. Гапонцева, Т. И. Чащухина, Л. М. Воронова, Л. И. Щинова, М. В. Дегтярев // Физика металлов и металловедение. - 2008. - № 4 (105). - C. 1-11. 